\title{
'Quality in, quality out', a stepwise approach to evidence-based medicine for rare diseases promoted by multiple endocrine neoplasia type 1
}

\author{
Dirk-Jan van Beek ${ }^{1}$, Rachel S van Leeuwaarde ${ }^{2}$, Carolina R C Pieterman ${ }^{2}$, Menno R Vriens ${ }^{1}$ and Gerlof D Valk ${ }^{2,3}$ \\ on behalf of the DutchMEN Study Group
}

\author{
${ }^{1}$ Department of Endocrine Surgical Oncology, University Medical Center Utrecht, Utrecht, The Netherlands \\ ${ }^{2}$ Department of Endocrine Oncology, University Medical Center Utrecht, Utrecht, The Netherlands \\ ${ }^{3}$ Parelsnoer Institute, Utrecht, The Netherlands \\ Correspondence should be addressed to G D Valk: g.d.valk@umcutrecht.nl
}

\begin{abstract}
Rare diseases pose specific challenges in the field of medical research to provide physicians with evidence-based guidelines derived from studies with sufficient quality. An example of these rare diseases is multiple endocrine neoplasia type 1 (MEN1), which is an autosomal dominant endocrine tumor syndrome with an estimated occurrence rate of 2-3 per 100,000. For this complex disease, characterized by multiple endocrine tumors, it proves difficult to perform both adequate and feasible studies. The opinion of patients themselves is of utmost importance to identify the gaps in the evidence-based medicine regarding clinical care. In the search for scientific answers to clinical research questions, the aim for best available evidence is obvious. Observational studies within patient cohorts, although prone to bias, seem the most feasible study design regarding the disease prevalence. Knowledge and adaptation to all types of bias is demanded in the strive for answers. Guided by our research on MEN1 patients, we elaborate on strategies to identify sufficient patients, to maximize and maintain patient enrolment and to standardize the data collection process. Preferably, data collection is performed prospectively, however, under certain conditions, data storage in a longitudinal retrospective database with a disease-specific framework is suitable. Considering the global challenges on observational research on rare diseases, we propose a stepwise approach from clinical research questions to scientific answers.
\end{abstract}

\author{
Key Words \\ - multiple endocrine \\ neoplasia type 1 \\ - hereditary tumor \\ syndrome \\ - research strategies \\ - database \\ - observational studies
}

\section{Introduction}

Rare diseases that affect less than one in 2000 people, pose challenges in supporting patients and physicians with evidence-based guidelines of sufficient quality (1). Medical decision making becomes challenging when guidelines are scarce or the underlying scientific evidence is meager.

Multiple endocrine neoplasia type 1 (MEN1) (OMIM 131100) is an autosomal dominant disease with an estimated occurrence rate of 2-3 per 100,000 (2). Due to the complexity of the disease, which is characterized by the development of multiple endocrine tumors already at an early age, developing evidence-based guidelines is a challenge (3). Most patients suffer from the classical triad of primary hyperparathyroidism (pHPT), duodenopancreatic neuroendocrine tumors (dp-NETs) and/or pituitary adenomas. The prevalence for pHPT, dp-NETs and https://ec.bioscientifica.com

https://doi.org/10.1530/EC-18-0359 (c) 2018 The authors Published by Bioscientifica Ltd

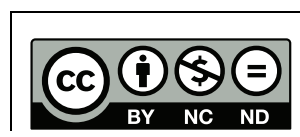

This work is licensed under a Creative Commons Attribution-NonCommercial-NoDerivatives 4.0 International License. 
pituitary tumors are 87,56 and $44 \%$, respectively in the Dutch population (4). Other encountered neoplasms include adrenal tumors, neuroendocrine tumors (NETs) of thymic, bronchial or gastric origin, skin and subcutaneous tumors, smooth muscle tumors and breast cancer $(5,6)$. Life expectancy of MEN1 patients is reduced compared to the general population (4). The prognosis of patients depends on early tumor detection and subsequent targeted interventions to prevent disease progression, making lifelong screening and intensive monitoring necessary (7).

Randomized controlled trials studying interventions and the optimal follow-up are almost impossible because of the low number of eligible patients for inclusion as well as the low yearly incidence of events in individual patients. Cohort studies are prone to various forms of bias such as selection bias, information bias and confounding by indication $(8,9)$.

Confronted by the principles of evidence-based medicine and need for high-quality scientific evidence regarding follow-up and interventions in MEN1, in the Netherlands in 2007, a retrospective MEN1 database was carefully designed. The aim was to answer multiple research questions that were based on the clinical dilemmas MEN1 patients and their treating physicians encountered in daily practice. The aim of this project was to provide patients and physicians with valid data. Considering the complexity of MEN1, a longitudinal database with a disease-specific framework was a necessity. Whereas strategies for conducting randomized controlled trials on rare diseases have been described, research methods for observational studies are far less developed (10). Guided by the fruitfulness of our longitudinal database and experience on this topic, this article will elaborate on our research strategy and observational study methods for rare diseases, describing the stepwise process from clinical research questions to scientific answers.

\section{Clinical dilemma and theoretical study design}

\section{Formulating research questions and determining study design}

Biomedical research consists of three main phases: formulating a research question, the collection of data based on these questions and the analysis of data. In recent years, the importance of the opinion of patients affected by the disease in this process is increasingly acknowledged. The subsequent study design is guided by a well-structured research question, addressing the study domain (patients with symptoms or a certain disease), determinant (diagnostic test, factor or therapy) and outcome of interest.

\section{MEN1 formulated research questions}

Clinical guidelines are only as good as the evidence and judgments they are based on (11). Even though there was a MEN1 consensus statement at the time, the scientific evidence underlying recommendations regarding screening and treatment of the different MEN1 manifestations was not always sufficient (12).

Our research group was confronted by a paucity of data on the natural course of the different MEN1 manifestations, prognostic factors, a genotypephenotype relation, the timing and effect of therapy and recommendations based on strong evidence for periodical screening for these manifestations. These topics were the basis of the first set of research questions (Table 1). In addition, we consulted the patient advocacy group in this stage of the process, as to which questions they deemed important to study. The patient advocacy group considered quality of life as an important topic to study. More specifically, they considered questions regarding frequency and content of follow-up visits, effects and complications of surgery (e.g. hypoparathyroidism after (sub)total parathyroidectomy) and survival of dp-NETs as important topics since these affect quality of life. In a process of informed shared decision-making, research questions and study aims were formulated thereafter.

\section{Study population}

\section{A single center patient population}

In the University Medical Center (UMC) Utrecht, approximately 80 MEN1 patients were identified in 2007, which can be regarded as a 'large' rare disease population. However large, this study population lacked power to detect meaningful differences. In addition, we considered the population as a possible source of selection bias, since our center is a national center of expertise in MEN possibly leading to a case-mix with more advanced stages of the disease. Improper selection of patients, not being representative for the target population, leads to selection bias. In general, minimizing selection bias is attempted by including as many patients as possible in terms of percentage from similar hospitals, regarding level of patient care, during the recruitment phase.

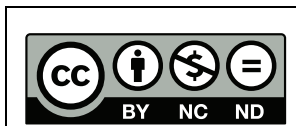
This work is licensed under a Creative Commons
Attribution-NonCommercial-NoDerivatives 4.0 International License. 

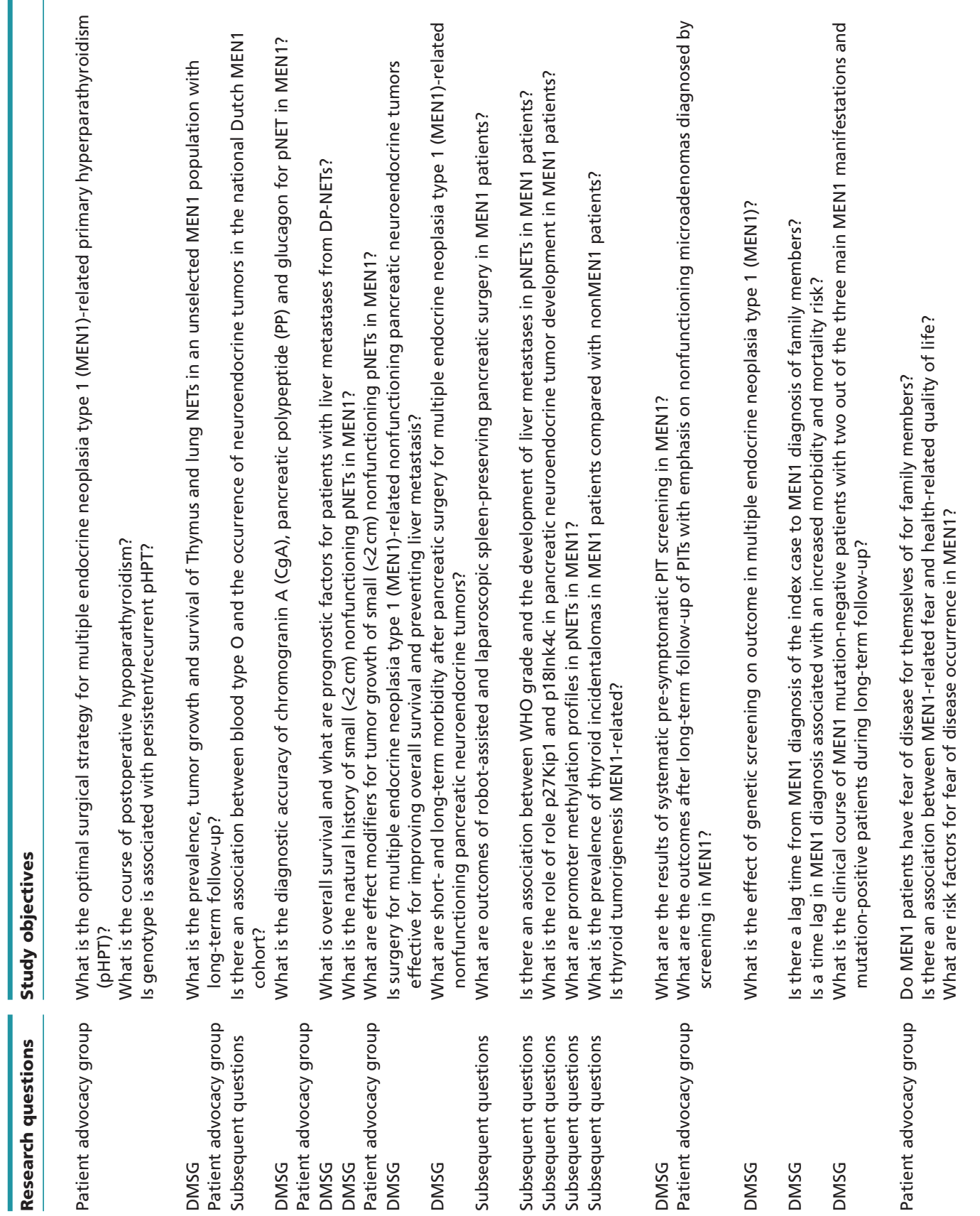

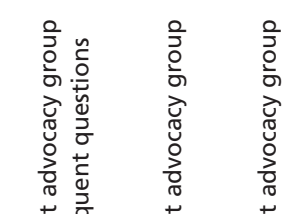

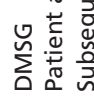

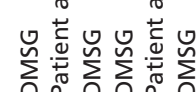
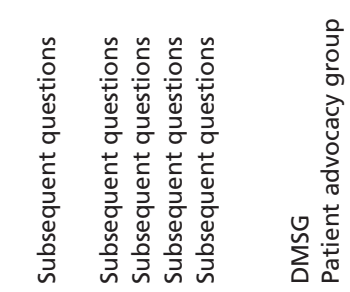

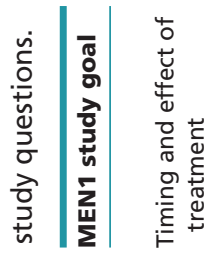
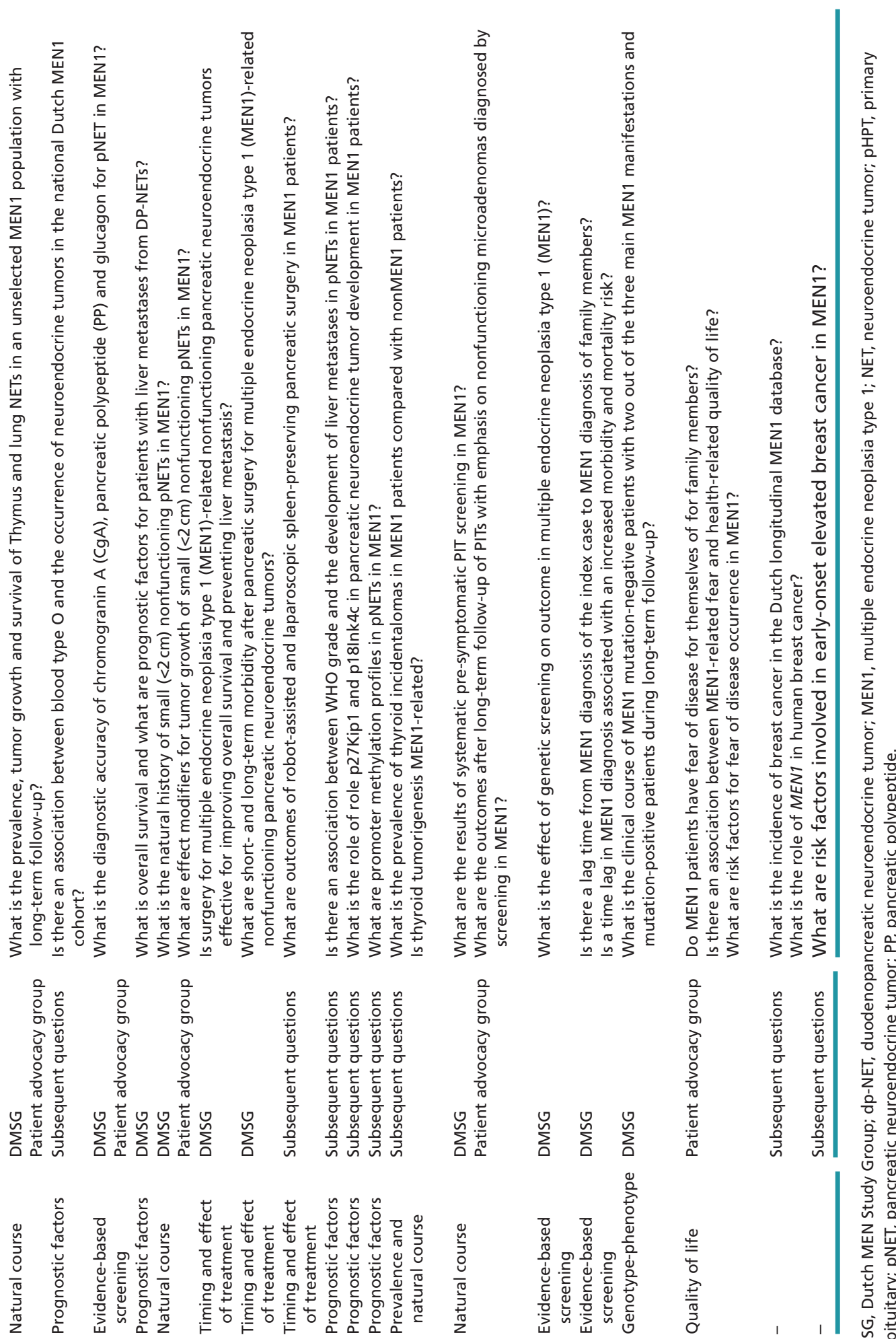

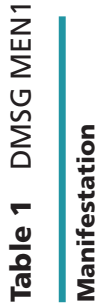

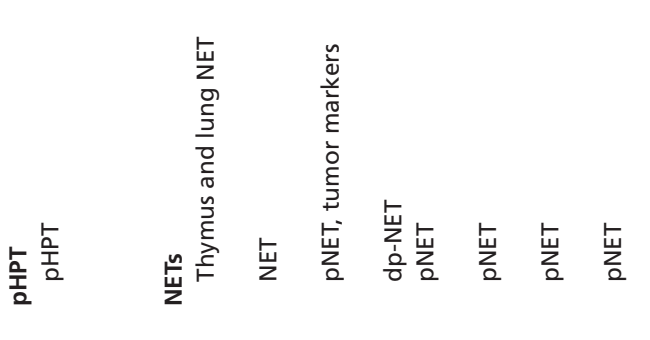

https://ec.bioscientifica.com

Cㅇ 2018 The authors 


\section{Collaboration at a national level}

In the Netherlands, MEN1 patients are commonly treated in a UMC (tertiary referral center) because of the necessity of a trained and dedicated multidisciplinary team (13). To include a representative sample of MEN1 patients and to increase sample size, a nationwide collaboration, known as the DutchMEN Study Group (DMSG), was initiated in 2008 (14). The DMSG consists of endocrinologists from every Dutch UMC, a consulting endocrine surgeon and representation from the patient advocacy group. Moreover, other specialist members of the multidisciplinary team are closely involved, which is in line with MEN1 guidelines to optimize patient care (13). The DMSG program, including patients from all Dutch UMCs, has led to the inclusion of over $90 \%$ of the total Dutch MEN1 population (> 400 participants) making it a true representation of Dutch MEN1 patients (15).

\section{Patient identification}

Before enrolling patients, a consistent diagnosis in accordance with guidelines is important. In this manner, a restricted population is created and selection bias is minimized. Using a standard identification method, MEN1 patients were identified by hospital diagnosis databases review. MEN1 diagnosis was based on clinical, familial or genetic criteria, based on clinical practice guidelines $(12,13)$. Less than $10 \%$ of the genetically diagnosed MEN1 patients is not included in the registry and only one person refused to participate. The high participation rate (over 90\%) has also been found in a survey of patients with leukodystrophies, another rare disease (16). However, for MEN1 populations, this registry participation rate is globally unique and thereby leading in the field.

\section{Strategies to maximize patient enrolment}

The urge for international data registries is expressed by The European Union Committee of Experts on Rare Diseases (17). Patients with rare diseases are generally easily accessible for participation in international data registries $(16,18)$. Since MEN1 is an autosomal dominant trait, patients' children have a 50\% chance of inheriting the disease (2). Patients are well aware of the high disease morbidity and decreased life expectancy since the disease 'runs in the family'. Patients maximize their contribution to medical research and subsequent clinical care for their affected relatives and other MEN1 patients.
Nevertheless, before patients are willing to engage in medical research, the physician-patient interaction is important $(16,19)$. In addition, to enroll a maximum number of patients, the study goals should be of direct importance to patients and their families. Active involvement of the national patient advocacy group in the DMSG from the stage of designing the research questions contributed to the high participation rate of patients.

\section{Obtaining informed consent}

The study protocol for the DMSG database and subsequent studies was approved by the Medical Ethical Committees of all UMCs in the Netherlands. The requirement to obtain individual informed consent was waived because of the retrospective and observational design. However, all patients received a letter including information regarding the collection and storage of clinical data and the possibility to refuse. From 2016 onward, the clinical database was continued prospectively including the collection of biobank materials (clinical biobank). Before inclusion in the clinical biobank, patients are informed by telephone or during an outpatient clinic visit including written patient information and asked to provide written informed consent. In addition, patients are informed about the possibility to withdraw their informed consent at any given time in the future.

\section{Strategies to maintain patient participation}

Studies with a necessary long-term follow-up are vulnerable to losing patients during follow-up. This potentially leads to follow-up bias, especially when the loss to follow-up differs between groups. Since MEN1 is a chronic disease in which patients have an ongoing risk for tumor development, patients consult endocrinologists annually, reducing follow-up bias to a minimum. However, patients that move to another place might change academic treatment center, decide to transfer to a local hospital or quit the follow-up regimen altogether. With respect to the nationwide collaboration of all Dutch UMCs in the DMSG, loss to follow-up of patients is mostly prevented. Changing academic center will not end nor interrupt data collection, because registry entry will continue from the new treatment hospital. Nevertheless, effort must be made to ensure regular physician consultations. DMSG strategies to minimize loss of follow-up include the physician-patient relation, and moreover, regular physician consultation is also promoted by the patient advocacy group.

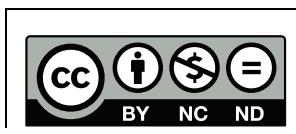
This work is licensed under a Creative Commons
Attribution-NonCommercial-NoDerivatives 4.0 International License. 
Strategies to establish the study population of the Dutch MEN1 registry are summarized in Table 2.

\section{From patients to data}

\section{The importance of data collection}

The goal of the data collection process is to gather data which give true and objective reflections of patients' conditions. Incorrect data or inconsistent data collection leads to information bias; therefore, the process of data collection must be carefully designed, conducted and preferably secured. Before the actual collection of data, it is important to understand the nature of the data, to classify the data and to decide to which extent data are collected. The quality of data is guided by validity and precision. Systematic errors in data collection are dangerous, since these lead to irreversible damage to the study's internal validity (20).

\section{Database design}

The construction of a structured database and the valid and precise collection of data were critical research steps (Table 3). Even though some single-center MEN1 studies were conducted in the UMC Utrecht, a well-structured process of data collection was absent $(21,22)$. In addition to the nationwide expansion of the study population, multicenter, nationwide collaboration on data collection was essential. Considering the urge for quick answers to clinical questions and the low disease prevalence, studies with prospective data collection seemed utopia. Therefore, a retrospective database was the first step to answer multiple research questions.

After setting the basis for national multi-institutional data gathering, the actual process of data collection and storage, based on national consensus, was the next step. Since multiple research questions were formulated for different MEN1 manifestations, a database to store

Table 2 DMSG study population strategies.

Study step

bias

Patient identification

Patient enrolment

Patient participation

\section{Recommendation}

- Nationwide collaboration

- Including comparable hospitals, e.g. tertiary referral centers

- Multicenter research

- Start (supra)national study group

- Consistent diagnosis according to guidelines

- Standardized identification method in hospital diagnosis databases

- Formulate study goals that are of direct importance to patients

- Patient advocacy group involvement from the start Recruitment of patients among members

- Prioritize research agenda/study questions

- Provide information among members/patients

- Familiarize medical research among members

- Yearly national and regional patient and specialist meetings

- Disease biology

- Autosomal dominant disorder

- Families willing to help affected relatives

- Knowledge on morbidity and mortality

- Informed consent

- Routine clinical care

- Trained and dedicated multidisciplinary treatment team

- One contact person for each institute

- Physician-patient relation

- Annual clinical consultation due to risk of tumor onset

- In case of hospital change

- Nationwide collaboration

- Continue registry in new treatment center

- International workshop on Multiple Endocrine Neoplasia (WorldMEN 2016, Utrecht, The Netherlands) including patient sessions

- Patient advocacy group

- Promote annual clinical consultation

- Yearly national and regional patient and specialist meetings

- Distribute research findings among patients

- Formulate new patient oriented questions
This work is licensed under a Creative Commons Attribution-NonCommercial-NoDerivatives 4.0 International License. 
individual patient data was carefully designed according to the disease characteristics and the formulated research questions. Many research questions addressed the frequency and timing of screening, thus knowledge of the natural history was demanded. Longitudinal data provide insight in the natural disease course. Therefore, data were collected retrospectively every quarter from 1990 to 2016.

This longitudinal, retrospective design was further developed to a MEN1 disease-specific framework. MEN1 patients have a lifetime risk to develop multiple endocrine tumors in multiple organs, each with a different penetrance. Since, there is no clear age-related penetrance for every manifestation and manifestations can occur at any given age, lifelong screening for all MEN1 manifestations is required $(7,23)$. Consequently, the process of diagnosis, therapy and follow-up is an ongoing, repeated and simultaneous process for MEN1-related neoplasms.

\section{Variable selection}

In line with the disease's complexity, a wide range of variables needed to be included in the database. Annual consultations include clinical and biochemical screening by specialized endocrinologists. Hormonally active tumors secrete different hormones, depending on the tumor's origin. Therefore, biochemical screening ranges from 72-h fast tests for pancreatic insulinomas to serum calcium levels for primary hyperparathyroidism. Radiological screening differs both in frequency and modality for different manifestations (13). Extensive additional diagnostic procedures may be performed when patients are suspected of a manifestation. Therapeutic interventions range from medical treatment to surgical resections, guided by manifestation, patient characteristics and disease stage.

Based on these factors and the formulated research questions a dataset was developed for each specific MEN1 manifestation (pHPT, dp-NETs, pituitary tumors, NETs (of stomach, bronchus and thymus) and adrenal lesions) including biochemical, radiological, surgical and pathology data (Table 4). Besides, datasets for general data on patient characteristics, medication use and previous medical history were designed. Multiple versions of these datasets were discussed among the study group participants and thereafter the final, total dataset was agreed upon.

Ahead of the collection of biochemical data from multiple hospitals, the planning on 'how to' collect these variables is essential, since clinical laboratories often harbor different measurement methods, leading to different units of measurement and reference values. Therefore, involvement of clinical chemistry laboratories of all participating centers is important during the design of the database. In addition, to compare these values during data analysis, a useful strategy is to express the values as upper level of the normal of the reference value, which is widely used in medical research.

\section{Data collection}

Variations during the data collection process, also known as observer bias, are remarkably reduced by securing the data collection process, minimizing the number of data collectors and collecting only uninterpreted or 'raw' data to prevent interpretation before statistical analysis. For example, there was no variable 'primary hyperparathyroidism' but, to define this variable, the outcomes of serum calcium and parathyroid hormone levels were used, so data were collected without knowledge of the outcomes. In addition, outcomes had to be subsequently found in individual patients during data analysis, hereby including the repetitive identification of a tumor over time as the reference standard for the diagnosis of a tumor (24). A central protocol was developed, which described per variable how it should be collected, so data collectors would gain familiarity with the appropriate gathering of data and interobserver variations were reduced. In the database, constraints were implemented for the range of outcomes that could be collected, preventing mistakes in data collection because of typing errors. Although the data collection in multicenter studies is commonly performed by researchers from every institution, only one or two centrally appointed data collectors were operating at a time. This minimized differences in data collection and enabled the collectors to gain vast experience in this large dataset, reducing intraobserver variability. The ideal geography of the Netherlands and centralizing the DMSG from Utrecht, optimized this way of data collection. All uncertainties during data collection and data capture were discussed with one principal investigator, which minimized defaults in these areas. These uncertainties were stored and are assessable at the present and in the future for the data collectors and researchers. The importance of protocolized data collection is the gathering of complete data, structurally the same in every center and for every patient, irrespective of disease severity. 
Table 3 DMSG recommendations for data storage and data collection.

\begin{tabular}{|c|c|}
\hline Study step & Recommendation \\
\hline Data storage & $\begin{array}{l}\text { - Web-based database } \\
\text { O Easily accessible from every hospital during data collection } \\
\text { - Confidentiality } \\
\text { ○ Pseudo-anonymize patients } \\
\text { ○.g. convert dates to quarters (e.g. } 1 \text { Q } 2010 \text { for all dates from January } 1^{\text {st }} \text { up to and including } \\
\text { March } 31^{\text {st }} \text { 2010) }\end{array}$ \\
\hline Database design & $\begin{array}{l}\text { - Urge for relatively quick answers } \\
\text { o Retrospective database design } \\
\text { - Study group consensus on database design } \\
\text { - Research questions on natural course of disease } \\
\text { ○ Longitudinal database design } \\
\text { ○ Quarterly collection of data } \\
\text { - Develop a disease-specific framework } \\
\text { - Epidemiological background: diagnostic, etiologic, prognostic and/or therapeutic aims } \\
\text { - Longitudinal design } \\
\text { ○ Repetitive collection of the same variables }\end{array}$ \\
\hline Variable selection & $\begin{array}{l}\text { - General data and considerations } \\
\text { ○ General patient data or demographics } \\
\text { ○ Raw or primary data } \\
\text { ○ Complex diseases and multiple research questions: more variables demanded } \\
\text { - Select disease-related variables } \\
\text { ○ Screening programs } \\
\text { ○ Different disease manifestations } \\
\text { ○ Biochemical, radiological, surgical and pathology data } \\
\text { - Study group consensus on variables } \\
\text { - Plan on how variables, such as laboratory values, should be collected in different hospitals } \\
\text { - Plan on how the 'raw' data can potentially be analyzed }\end{array}$ \\
\hline Data collection & $\begin{array}{l}\text { - General steps } \\
\text { C Collect raw data } \\
\text { Compulsory variables } \\
\circ \text { Implement constraints in the database } \\
\circ \text { Data capture control among data collectors } \\
\circ \text { One principal investigator } \\
\text { Discuss uncertainties } \\
\text { - Document and store these decisions } \\
\text { - Develop a central protocol to facilitate standardized data collection } \\
\text { - Data are consistently captured appropriately } \\
\text { - Minimize number of data collectors at a time } \\
\circ \text { Data collectors will gain familiarity with the database } \\
\circ \text { Select data collectors with affinity for the project, e.g. PhD students using the data for their } \\
\text { thesis } \\
\text { Provide data collectors with enough time to collect data }\end{array}$ \\
\hline
\end{tabular}

\section{Data storage}

Nowadays, the use of an easily accessible electronic, webbased application facilitates the collection of data in multicenter studies. However, security issues regarding patient data are of utmost importance. Concerning confidentiality, patients were pseudo-anonymized upon inclusion in the database, where every patient received a unique identification code, which is available for future data collection at the participating hospital. Regarding the low disease prevalence, all dates were converted into a quarter of a year (e.g. 1 Q 2010 for all dates from January 1 up to and including March 31, 2010). In addition to the simplification of data collection, electronic registries offer the opportunity of direct data output for all involved researchers.

\section{Missing data}

Retrospective studies are vulnerable for missing data, which lead to bias if the missing data are related to the outcome or exposure of interest. By securing the data collection, the quarterly collection of data and the available data from annual consultations, missing data https://ec.bioscientifica.com

https://doi.org/10.1530/EC-18-0359 (c) 2018 The authors Published by Bioscientifica Ltd
This work is licensed under a Creative Commons Attribution-NonCommercial-NoDerivatives 4.0 International License. 

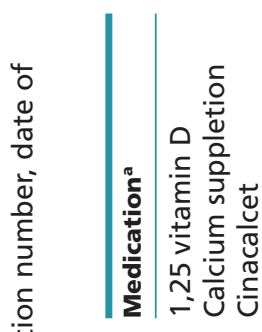

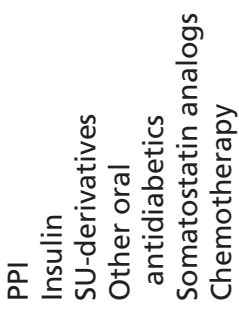
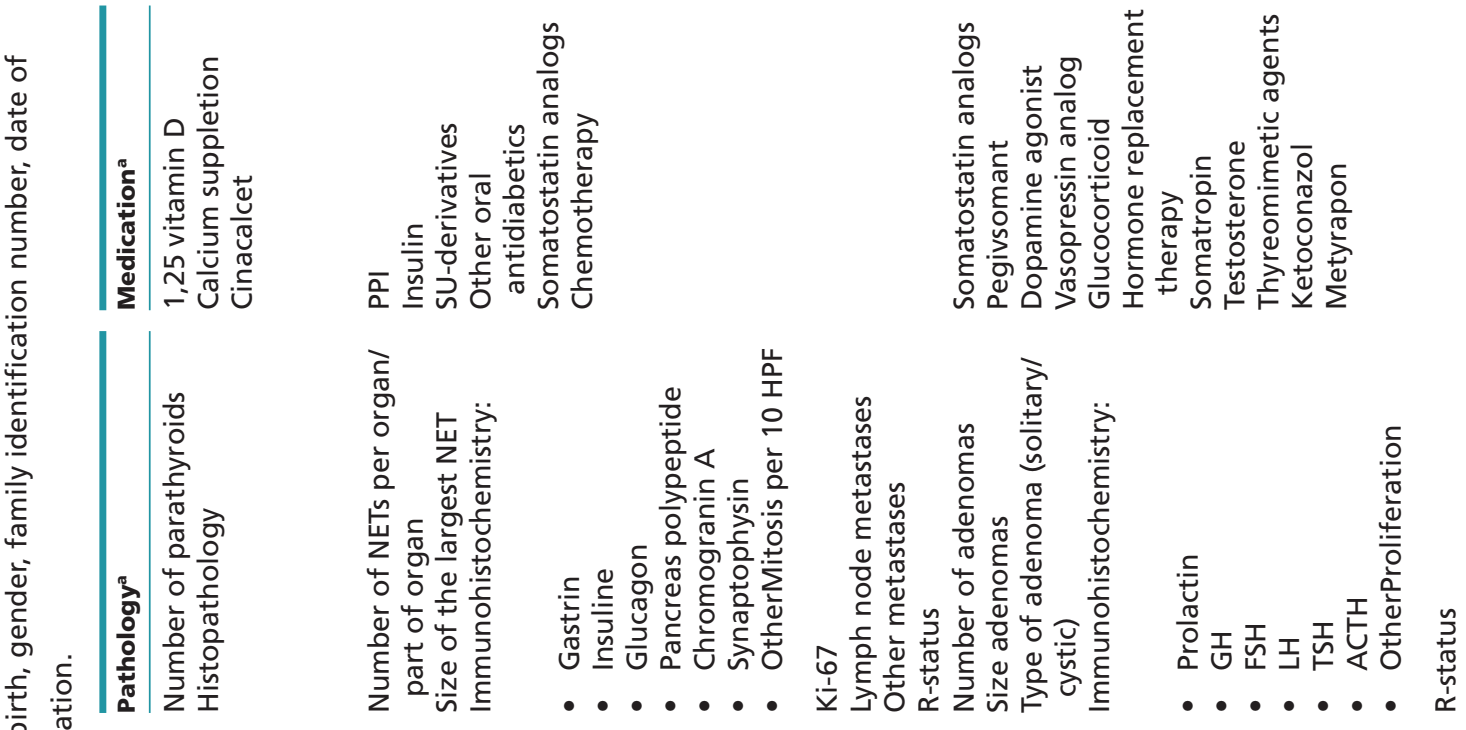

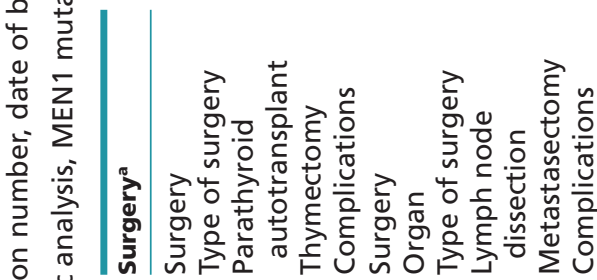

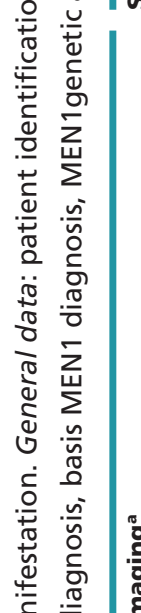

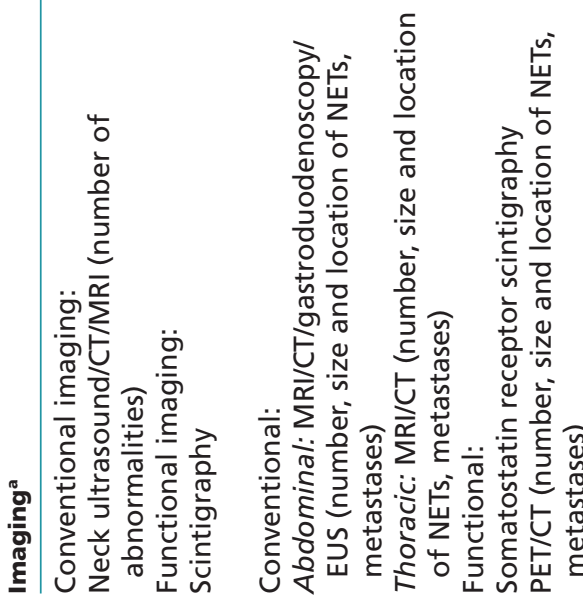

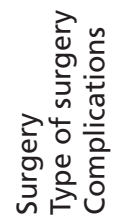
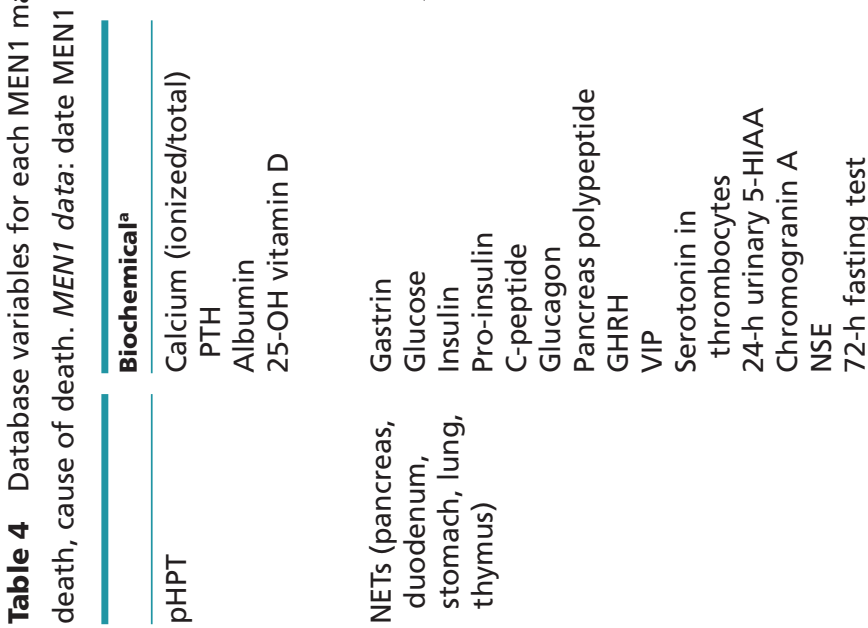

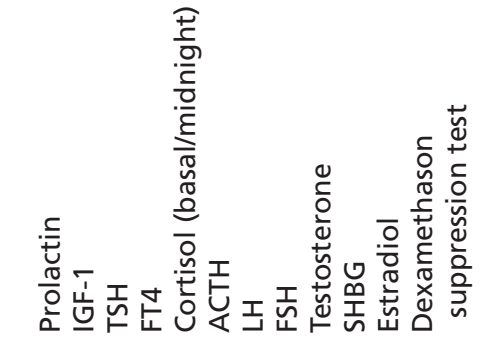

๑ 2018 The authors Published by Bioscientifica Ltd

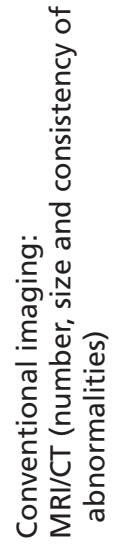




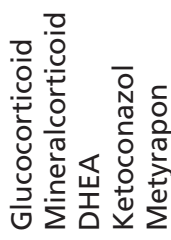

$\div \frac{0}{\circ}$

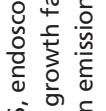

岂灾

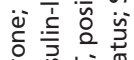

인

兽要

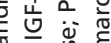

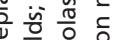

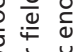

(1)

崖 囱

$\tilde{\pi}$

पे

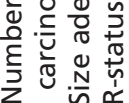

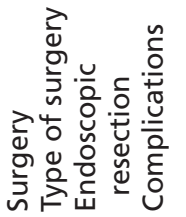

were minimized. Nevertheless, prospective data collection will further reduce missing data.

\section{Time aspects}

Longitudinal studies covering a long time span, might encounter changes in care due to increased technology and medical knowledge. In case variations in care or measurement of determinants or outcomes lead to systematic differences between patients over time, detection bias exists. Considering the numerous manifestations and the longitudinal study design, detection bias is lurking for all MEN1 manifestations, since biochemical and radiological diagnostics have gained increased sensitivity and specificity over the years. With an increase in frequency and quality of screening, manifestations are detected in earlier disease stages. Stratifying patients into birth cohorts, to minimize the effects of detection bias, has been previously performed in a longitudinal study (23). Nevertheless, by including patients from 1990 onward, differences in diagnostic opportunities and therapies are reduced, compared to studies including patients over a longer time span.

\section{The DMSG contributions to patient care}

Up till now, publications from the retrospective database have already answered many of our research questions and clinical management has changed Table $5(4,6,7$, $14,24,25,26,27,28,29,30,31,32,33,34,35,36,37$, 38,39 ). Moreover, the retrospective study design proved to be suitable, since a long latency between exposure and outcome exists. Most important findings from the DMSG research include the decreased life expectancy, the natural course of NETs (lung, thymus and pancreas) and pituitary adenomas, the effect of periodical screening and the surgical outcomes including complications of nonfunctioning pancreatic NETs $(4,14,24,26,30,33$, $35)$. Another example from our database is the increased breast cancer risk for women with MEN1 compared to the general population (Risk Ratio of 2.8) (6).

\section{Current state and future perspectives}

\section{Designing a prospective database}

Prospective data collection will further reduce the number of missing data, increase the quality of data, enable the collection of baseline characteristics and unknown https://ec.bioscientifica.com https://doi.org/10.1530/EC-18-0359
C) 2018 The authors Published by Bioscientifica Ltd
This work is licensed under a Creative Commons Attribution-NonCommercial-NoDerivatives 4.0 International License. 
Table 5 DMSG contributions to clinical care.

\section{Title}

Multiple endocrine neoplasia type 1

(MEN1): its manifestations and effect of genetic screening on clinical outcome (7)

Primary hyperparathyroidism in MEN1 patients: a cohort study with long-term follow-up on preferred surgical procedure and the relation with genotype (25)

Low accuracy of tumor markers for diagnosing pancreatic neuroendocrine tumors in multiple endocrine neoplasia type 1 patients (14)

Natural course and survival of neuroendocrine tumors of thymus and lung in MEN1 patients (26)

Breast cancer predisposition in multiple endocrine neoplasia type 1 (6)

Thyroid incidentalomas in patients with multiple endocrine neoplasia type 1 (28)

No association of blood type $\mathrm{O}$ with neuroendocrine tumors in multiple endocrine neoplasia type 1 (29)

Long-term natural course of pituitary tumors in patients with MEN1: results from the DutchMEN1 Study Group (DMSG) (30)

Impact of delay in diagnosis in outcomes in MEN1: results from the Dutch MEN1 Study Group (31)

Robot-assisted spleen preserving pancreatic surgery in MEN1 patients (32)

\section{Study objectives}

To determine the effect of genetic screening on outcome in multiple endocrine neoplasia type 1 (MEN1)

To identify the optimal surgical strategy for multiple endocrine neoplasia type 1 (MEN1)-related primary hyperparathyroidism (pHPT)

To describe the course of postoperative hypoparathyroidism and to assess whether genotype is associated with persistent/ recurrent pHPT

To assess the diagnostic accuracy of chromogranin A $(\mathrm{CgA})$, pancreatic polypeptide (PP), and glucagon for pNET in MEN1

To assess prevalence, tumor growth, and survival of Thymus and lung NETs in an unselected MEN1 population with long-term follow-up

To clarify the role of MEN1 in human breast cancer

To assess the incidence of breast cancer in the Dutch longitudinal MEN1 database

To assess the prevalence of thyroid incidentalomas in MEN1 patients compared with nonMEN1 patients

To verify whether thyroid tumorigenesis is MEN1-related

To assess the association between blood type $\mathrm{O}$ and the occurrence of neuroendocrine tumors in the national Dutch MEN1 cohort

To assess the results of systematic presymptomatic PIT screening and subsequent long-term follow-up of PITs with emphasis on nonfunctioning microadenomas diagnosed by screening

To assess whether there is a lag time from MEN1 diagnosis of the index case to MEN1 diagnosis of family members

To determine whether this lag time was associated with an increased morbidity and mortality risk

To describe robot-assisted and laparoscopic spleen-preserving pancreatic surgery in MEN1 patients, and to compare both techniques

\section{Outcomes/new insights}

Genetic diagnosis is associated with less morbidity at diagnosis and at follow-up

Early genetic diagnosis might therefore lead to improvement of long-term outcome

SPTX with bilateral transcervical thymectomy is the procedure of choice for MEN1-related PHPT. Genotype seems to affect the chance of recurrence. Postoperative hypoparathyroidism lasting 6 months or more should not be considered permanent in MEN

The diagnostic accuracy of the tumor markers $\mathrm{CgA}, \mathrm{PP}$, and glucagon for pNET in MEN1 is low

In MEN1 patients, Thymus NETs almost exclusively occurred in males and had a very low prevalence and a high mortality. Lung NETs occurred more often than previously thought, had an indolent course, and occurred equally in both sexes. Tumor growth in males was double compared with female patients

Female patients with MEN1 are at increased risk for breast cancer

Our observations indicate that MEN1 mutations are involved in human breast carcinogenesis Intensified breast cancer screening at a relatively young age should be considered in female patients with MEN1 MEN1 patients do not have a higher prevalence of thyroid incidentalomas compared with primary hyperparathyroidism patients without the diagnosis of MEN1. Menin was expressed in the thyroid tumors of MEN1 patients

An association between blood type $\mathrm{O}$ and the occurrence of neuroendocrine tumors in MEN1 patients was not confirmed. For this reason, the addition of the blood type to screening and surveillance practice seems not to be of additional value for identifying MEN1 patients at risk for the development of neuroendocrine tumors, metastatic disease, or a shortened survival

Systematic pre-symptomatic screening for PIT in patients with MEN1 predominantly results in detection of nonfunctioning microadenomas. Prolactinoma in patients with MEN1 responded well to medical treatment. Microadenomas grew only occasionally and after many years without clinical consequences. Frequent magnetic resonance imaging follow-up of nonfunctioning microadenomas in the context of MEN1 and sporadically occurring PITs therefore seems debatable

There is a clinically relevant delay in MEN1 diagnosis in families because of a lag time between the diagnosis of an index case and the rest of the family. More emphasis should be placed on the conduct of proper counseling and genetic testing in all eligible family members

Minimally invasive spleen-preserving surgery in MEN1 patients is safe and feasible. Patients who underwent robot-assisted surgery did not require conversion to open surgery
C 2018 The authors Published by Bioscientifica Ltd

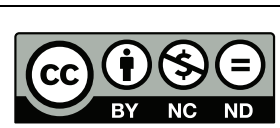

This work is licensed under a Creative Commons Attribution-NonCommercial-NoDerivatives 4.0 International License. 
Table 5 Continued.

Title
Early and late complications after
surgery for MEN1-related
nonfunctioning pancreatic
neuroendocrine tumors (33)
MEN1 redefined, a clinical
comparison of mutation-positive
and mutation-negative
patients (4)

Prognostic factors for survival of MEN1 patients with duodenopancreatic tumors metastatic to the liver: results from the DMSG (34)

Management of MEN1 related nonfunctioning pancreatic NETs: a shifting paradigm: results from the DutchMEN1 Study Group (35)

MEN1-dependent breast cancer: indication for early screening? Results from the Dutch MEN1 Study Group (36)

Prognostic value of WHO grade in pancreatic neuro-endocrine tumors in multiple endocrine neoplasia type 1: results from the DutchMEN1 Study Group (38)

Long-term natural course of small nonfunctional pancreatic neuroendocrine tumors in MEN1-results from the Dutch MEN1 Study Group (24)

Expression of p27Kip1 and p18Ink4c in human multiple endocrine neoplasia type 1-related pancreatic neuroendocrine tumors (39)

High fear of disease occurrence is associated with low quality of life in patients with multiple endocrine neoplasia type 1: results from the Dutch MEN1 Study Group (41)

DNA methylation profiling in MEN1 related pancreatic neuroendocrine tumors reveals a potential epigenetic target for treatment (42)

\section{Study objectives}

To estimate short and long-term morbidity after pancreatic surgery for multiple endocrine neoplasia type 1 (MEN1)-related nonfunctioning pancreatic neuroendocrine tumors (NF-pNETs)

To describe and compare the clinical course of MEN1 mutation-negative patients with two out of the three main MEN1 manifestations and mutation-positive patients during long-term follow-up

To determine overall survival and prognostic factors for patients with liver metastases from DP-NETs

To assess if surgery for multiple endocrine neoplasia type 1 (MEN1) related nonfunctioning pancreatic neuroendocrine tumors (NF-pNETs) is effective for improving overall survival and preventing liver metastasis

To assess whether other risk factors are involved to identify MEN1 at greatest risk for early-onset elevated breast cancer

To assess the prognostic value of WHO grade in MEN1-related pancreatic neuroendocrine tumors

To assess long-term natural history of small NF-pNETs and its modifiers in the Dutch MEN1 population

To assess the role of role $\mathrm{p} 27 \mathrm{Kip} 1$ and p18Ink4c in MEN1-related pancreatic neuroendocrine tumor development

To assess whether MEN1 leads to psychological distress because of fear of disease occurrence (FDO), and affects quality of life

To determine promoter methylation profiles in MEN1-related pNETs

\section{Outcomes/new insights}

MEN1 NF-pNET surgery is associated with high rates of major short and long-term complications. Current findings should be taken into account in the shared decision-making process when MEN1 NF-pNET surgery is considered

Mutation-positive and mutation-negative MEN1 patients have a different phenotype and clinical course. Mutationnegative patients develop MEN1 manifestations at higher age and have a life expectancy comparable with the general population. The apparent differences in clinical course suggest that MEN1 mutation-negative patients do not have true MEN1, but another MEN1-like syndrome or sporadic co-incidence of two neuro-endocrine tumors Despite the fairly indolent course of DP-NET liver metastases in MEN1 patients, half of the population was deceased after 10 years. Sex and tumor load at diagnosis of liver metastases are possible prognostic factors for worse survival

MEN1 patients with NF-pNETs $<2 \mathrm{~cm}$ can be managed by watchful waiting, hereby avoiding major surgery without loss of oncological safety. The beneficial effect of a surgery in NF-pNETs 2 to $3 \mathrm{~cm}$ requires further research. In patients with NF-pNETs $>3 \mathrm{~cm}$, watchful waiting seems not advisable

The increased breast cancer risk in MEN1 carriers was not related to other known breast cancer risk factors or familial cancer history, and therefore breast cancer surveillance from the age of 40 years for all women with MEN1 is justifiable

High mitotic count is correlated with poor prognosis in MEN1 patients with large nonfunctioning pNETs

The majority of small NF-pNETs are stable at long-term follow-up, irrespective of the underlying MEN1 genotype. A subgroup of tumors is slowly growing but cannot be identified on clinical grounds. In this subgroup, tumors with missense mutations exhibited faster growth. Additional events appear necessary for pNETs to progress. Future studies should be aimed at identifying these molecular driving events, which could be used as potential biomarkers

These findings indicate that loss of p18Ink4c, but not p27Kip1, is a common event in the development of MEN1-related pNETs. Restoration of p18Ink4c function through CDK4/6 inhibitors could be a therapeutic option for MEN1-related pNETs

The majority of patients with MEN1 have FDO for themselves and even more for their relatives. This psychological distress is associated with a lower health-related quality of life. Therefore, in the medical care for MEN1, emphasis should also be placed on FDO and quality of life

Promoter hypermethylation is a frequent event in MEN1-related and sporadic pNETs. Targeting DNA methylation could be of therapeutic value in MEN1 patients with advanced pNETs

CgA, chromogranin A; DMSG, Dutch MEN Study Group; DP-NET, duodenopancreatic neuroendocrine tumor; FDO, fear of disease occurrence; MEN1, multiple endocrine neoplasia type 1; NET, neuroendocrine tumor; NF-pNETs, nonfunctioning pancreatic neuroendocrine tumor; pHPT, primary hyperparathyroidism; PIT, pituitary; pNET, pancreatic neuroendocrine tumor; PP, pancreatic polypeptide; SPTX, subtotal parathyroidectomy.

https://ec.bioscientifica.com https://doi.org/10.1530/EC-18-0359 (c) 2018 The authors Published by Bioscientifica Ltd

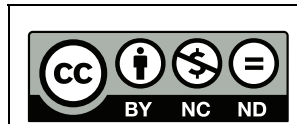

This work is licensed under a Creative Commons Attribution-NonCommercial-NoDerivatives 4.0 International License. 
Table 6 DMSG overview of study phases and recommendations.

Study phase
1. Formulating research questions
Formulate research questions
2. Patient inclusion
a. Increase sample size
b. Identify patients
c. Maximize patient enrolment

d. Maintain patient participation
Recommendation

Involvement of patient advocacy group

National multicenter collaboration and study group

- Diagnosis according to clinical practice guidelines

- Standardized identification method in participating centers

- Formulate patient relevant study aims

- Involvement of patient advocacy group

Recruitment of patients among members

1. Familiarize medical research among members

- Continue registry entry in new treatment center

- Optimize physician-patient relation in routine clinical care

- Patient advocacy group

Distribute research findings among patients

2. Yearly patient and specialist meetings

- Web-based database

3. Data storage and data collection

a. Data storage

b. Database design

c. Variable selection

d. Data collection

- Maintain confidentiality in accordance with local legislation

- Consider study design

- Consider epidemiologic type of research questions

- Develop a disease-specific framework

- Raw data

- Select disease-related variables

- Reach consensus on data in study group

- Plan how variables, such as laboratory values, should be collected in different hospitals

- Develop a central protocol to facilitate standardized data collection

- Minimize number of data collectors at a time

4. Designing a prospective database based on outcomes of the retrospective database
a. User-friendliness
b. Supranational collaboration
c. Continuously update database

\section{Biobanking}

a. National collaboration

b. Decide on materials

c. Link to clinical data
- Automatic data capture from hospital records

- Add indicator variables of manifestations for cross-sectional identification of patients to plan supranational studies

- Include new variables based on new research questions or advances in care

- Establish central organization/collaboration between UMCs

- Create centralized biobanking protocol including all phases: collection, pre-analysis, registration, processing and storage of the samples

- Sites of tissue collection and storage

E.g. in individual UMC biobanks

- Choices on which patient materials to collect Blood, tissue, feces, urine and others

- Plan on how to collect materials

Routine patient care or in research setting

- Preferably implement link to clinical data confounders. Therefore, the database is continued prospectively to enhance future MEN1 research based on the outcomes of the retrospective database. The design of the prospective database focuses on user-friendliness by using a new Web-based platform, which offers the opportunity to physicians to enter data during routine care and to automatically capture laboratory values from patient hospital records. Consequently, according to research findings, new research questions and advances in diagnostic and therapeutic regimen, several variables are added such as the breast cancer screening, bone density measurements, nuclear imaging and therapy and

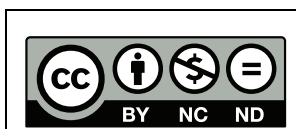

This work is licensed under a Creative Commons Attribution-NonCommercial-NoDerivatives 4.0 International License. 
surgical techniques. In addition, some indicator variables are added for the manifestations, so cross-sectional prevalence estimates can easily be obtained, which are useful for planning supranational research projects and imaginably a global RCT in the future. In addition to clinical data collection, patient material is obtained and stored in the biobanks of all UMCs to enable future basal and translational research. Assembled MEN1 patient materials include blood (serum, EDTA and citrate plasma and DNA) and tissue (formalin-fixed paraffinembedded and fresh frozen) of biopsies and resected specimen (40). Materials are preferably obtained during routine patient care.

\section{The Parelsnoer Institute}

This clinical database and biobank initiative is now part of the Parelsnoer Institute (PSI) (http://www.parelsnoer. org/page/en/Home), which is part of the Netherlands Federation of UMCs (40). Within the framework of PSI, individual UMC clinical biobanks store patient materials according to a standardized national biobanking protocol, covering all phases of biobanking: collection, pre-analysis, registration, processing and storage of the samples (40). These data are centrally stored and linked to the clinical patient data. Clinical data are either manually captured, however, automatic data capture options are available for certain variables, such as laboratory tests (40). The connection between clinical and biobank data offers the unique opportunity to study genetic and epigenetic factors driving hereditary NETs. Identification of these factors in familial tumors, could in the future be extrapolated to sporadic NETs to identify NETs with an unfavorable prognosis and offer specific new targets for therapeutic opportunities.

\section{Conclusion}

Guided by our MEN1 experiences, we propose a stepwise approach from clinical research questions to scientific answers (Table 6). This experience can guide others planning to start a database for rare diseases. Involvement of the patients themselves from the beginning leads to meaningful research questions guiding clinical care and, in addition, increases the participation rate, thereby minimizing selection bias. Thereafter, the protocolized and standardized process of data collection and data storage into a disease-specific database enables the collection of homogeneous data and reducing information bias. Ongoing prospective clinical data collection and the collection of biobank materials has commenced in 2016, which will further increase the quality of the data and enables clinical epidemiological and translational research in the near future. This will directly impact patient care and provide new insights into MEN1 in the future.

\section{Declaration of interest}

G D V is scientific director of the Parelsnoer Institute, the Netherlands, which is a non-profit organization of the Netherlands Federation of University Medical Centers. G D V did not receive any funding from Parelsnoer Institute for this manuscript. The other authors declare that they have no conflict of interest that could be perceived as prejudicing the impartiality of the research reported.

\section{Funding}

This work did not receive any specific grant from any funding agency in the public, commercial or not-for-profit sector.

\section{Author contribution statement}

D-J $\vee$ B: Study design, drafting the manuscript and final approval of the manuscript. R S v L: Study design, drafting the manuscript and final approval of the manuscript. C R C P: Database design, critical revision and final approval of the manuscript. M R V: Study design, critical revision and final approval of the manuscript. G D V: Study design, database design, critical revision and final approval of the manuscript. All authors read and approved the final manuscript.

\section{Acknowledgements}

Collaborators: All individuals listed as collaborators participated in the DutchMEN Study Group from its establishment, thereby putting significant effort in the formation of the DMSG, patient recruitment on a national level, formulation of research questions and variable selection. Members of the DutchMEN Study Group (DMSG) at its establishment in alphabetical order: P H Bisschop, MD, Ph.D., Amsterdam UMC, Amsterdam, The Netherlands. I H M Borel Rinkes, MD, Ph.D., University Medical Center Utrecht, Utrecht, The Netherlands. O M Dekkers, MD, Ph.D., Leiden University Medical Center, Leiden, The Netherlands. M L Drent, MD, Ph.D., Amsterdam UMC, Amsterdam, The Netherlands. B Havekes, MD, Ph.D., Maastricht University Medical Center, Maastricht, The Netherlands. W W de Herder, MD, Ph.D., Erasmus Medical Center, Rotterdam, The Netherlands. A R M M Hermus, MD, Ph.D., Radboud University Medical Center, Nijmegen, The Netherlands. A N A van der Horst-Schrivers, MD, Ph.D., University Medical Center Groningen, Groningen, The Netherlands. J de Jong, President of the Dutch MEN patient advocacy group (Belangengroep MEN), the Netherlands. H F A Vasen, MD, Ph.D., Netherlands Foundation for the Detection of Hereditary Tumours, the Netherlands. B A Zonnenberg, MD, Ph.D., University Medical Center Utrecht, the Netherlands.

\section{References}

1 Lilford RJ, Thornton JG \& Braunholtz D. Clinical trials and rare diseases: a way out of a conundrum. BMJ 1995311 1621-1625 (https://doi.org/10.1136/bmj.311.7020.1621)

2 Chandrasekharappa SC, Guru SC, Manickam P, Olufemi SE, Collins FS, Emmert-Buck MR, Debelenko LV, Zhuang Z, Lubensky IA, Liotta LA, et al. Positional cloning of the gene for multiple

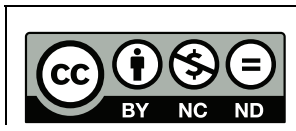

This work is licensed under a Creative Commons Attribution-NonCommercial-NoDerivatives 4.0 International License. 
endocrine neoplasia-type 1. Science 1997276 404-407. (https://doi. org/10.1126/science.276.5311.404)

3 Goudet P, Dalac A, Le Bras M, Cardot-Bauters C, Niccoli P, LévyBohbot N, Du Boullay H, Bertagna X, Ruszniewski P, BorsonChazot F, et al. MEN1 disease occurring before 21 years old: a 160-patient cohort study from the Groupe d'étude des Tumeurs Endocrines. Journal of Clinical Endocrinology and Metabolism 2015100 1568-1577. (https://doi.org/10.1210/jc.2014-3659)

4 de Laat JM, van der Luijt RB, Pieterman CRC, Oostveen MP, Hermus AR, Dekkers OM, de Herder WW, van der Horst-Schrivers AN, Drent ML, Bisschop PH, et al. MEN1 redefined, a clinical comparison of mutation-positive and mutation-negative patients. BMC Medicine 201614 182. (https://doi.org/10.1186/s12916-016-0708-1)

5 Goudet P, Murat A, Binquet C, Cardot-Bauters C, Costa A, Ruszniewski P, Niccoli P, Ménégaux F, Chabrier G, Borson-Chazot F, et al. Risk factors and causes of death in MEN1 disease. A GTE (Groupe d'Etude des Tumeurs Endocrines) cohort study among 758 patients. World Journal of Surgery 201034 249-255. (https://doi. org/10.1007/s00268-009-0290-1)

6 Dreijerink KMA, Goudet P, Burgess JR, Valk GD, International Breast Cancer in MEN1 Study Group. Breast-cancer predisposition in multiple endocrine neoplasia type 1. New England Journal of Medicine 2014371 583-584. (https://doi.org/10.1056/NEJMc1406028)

7 Pieterman CRC, Schreinemakers JMJ, Koppeschaar HPF, Vriens MR, Borel Rinkes IHM, Zonnenberg BA, van der Luijt RB \& Valk GD. Multiple endocrine neoplasia type 1 (MEN1): its manifestations and effect of genetic screening on clinical outcome. Clinical Endocrinology 200970 575-581. (https://doi.org/10.1111/j.13652265.2008.03324.x)

8 Sorensen HT, Lash TL \& Rothman KJ. Beyond randomized controlled trials: a critical comparison of trials with nonrandomized studies. Hepatology 200644 1075-1082. (https://doi.org/10.1002/ hep.21404)

9 Grimes DA \& Schulz KF. Bias and causal associations in observational research. Lancet 2002359 248-252. (https://doi.org/10.1016/S01406736(02)07451-2)

10 Gagne JJ, Thompson L, O'Keefe K \& Kesselheim AS. Innovative research methods for studying treatments for rare diseases: methodological review. BMJ 2014349 g6802. (https://doi. org/10.1136/bmj.g6802)

11 Atkins D, Best D, Briss PA, Eccles M, Falck-Ytter Y, Flottorp S, Guyatt GH, Harbour RT, Haugh MC, Henry D, et al. Grading quality of evidence and strength of recommendations. BMJ 20043281490. (https://doi.org/10.1136/bmj.328.7454.1490)

12 Brandi ML, Gagel RF, Angeli A, Bilezikian JP, Beck-Peccoz P, Bordi C, Conte-Devolx B, Falchetti A, Gheri RG, Libroia A, et al. Guidelines for diagnosis and therapy of MEN type 1 and type 2. Journal of Clinical Endocrinology and Metabolism 200186 5658-5671. (https://doi. $\operatorname{org} / 10.1210 /$ jcem.86.12.8070)

13 Thakker RV, Newey PJ, Walls GV, Bilezikian J, Dralle H, Ebeling PR, Melmed S, Sakurai A, Tonelli F, Brandi ML, et al. Clinical practice guidelines for multiple endocrine neoplasia type 1 (MEN1). Journal of Clinical Endocrinology and Metabolism 201297 2990-3011. (https:// doi.org/10.1210/jc.2012-1230)

14 de Laat JM, Pieterman CRC, Weijmans M, Hermus AR, Dekkers OM, de Herder WW, van der Horst-Schrivers ANA, Drent ML, Bisschop PH, Havekes B, et al. Low accuracy of tumor markers for diagnosing pancreatic neuroendocrine tumors in multiple endocrine neoplasia type 1 patients. Journal of Clinical Endocrinology and Metabolism 2013 98 4143-4151. (https://doi.org/10.1210/jc.2013-1800)

15 de Laat JM, Tham E, Pieterman CRC, Vriens MR, Dorresteijn JAN, Bots ML, Nordenskjöld M, van der Luijt RB \& Valk GD. Predicting the risk of multiple endocrine neoplasia type 1 for patients with commonly occurring endocrine tumors. European Journal of Endocrinology, European Federation of Endocrine Societies 2012167 181-187. (https://doi.org/10.1530/EJE-12-0210)
16 Darquy S, Moutel G, Lapointe AS, D'Audiffret D, Champagnat J, Guerroui S, Vendeville ML, Boespflug-Tanguy O \& Duchange N. Patient/family views on data sharing in rare diseases: study in the European LeukoTreat project. European Journal of Human Genetics? 201624 338-343. (https://doi.org/10.1038/ejhg.2015.115)

17 Aymé S, Rodwell C \& The European Union Committee of Experts on Rare Diseases. The European Union Committee of Experts on Rare Diseases: three productive years at the service of the rare disease community. Orphanet Journal of Rare Diseases 20149 30. (https://doi. org/10.1186/1750-1172-9-30)

18 McCormack P, Kole A, Gainotti S, Mascalzoni D, Molster C, Lochmüller H \& Woods S. 'You should at least ask'. the expectations, hopes and fears of rare disease patients on large-scale data and biomaterial sharing for genomics research. European Journal of Human Genetics 201624 1403-1408. (https://doi.org/10.1038/ejhg.2016.30)

19 Bendixen RM, Morgenroth LP \& Clinard KL. Engaging participants in rare disease research: a qualitative study of Duchenne muscular dystrophy. Clinical Therapeutics 201638 1474-1484. (https://doi. org/10.1016/j.clinthera.2016.04.001)

20 Carlson MDA \& Morrison RS. Study design, precision, and validity in observational studies. Journal of Palliative Medicine 200912 77-82. (https://doi.org/10.1089/jpm.2008.9690)

21 Vasen HF, Lamers CB \& Lips CJ. Screening for the multiple endocrine neoplasia syndrome type I. A study of 11 kindreds in the Netherlands. Archives of Internal Medicine 1989149 2717-2722 (https://doi.org/10.1001/archinte.149.12.2717)

22 Geerdink EAM, Van der Luijt RB \& Lips CJM. Do patients with multiple endocrine neoplasia syndrome type 1 benefit from periodical screening? European Journal of Endocrinology 2003149 577-582 (https://doi.org/10.1530/eje.0.1490577)

23 Machens A, Schaaf L, Karges W, Frank-Raue K, Bartsch DK, Rothmund M, Schneyer U, Goretzki P, Raue F \& Dralle H. Age-related penetrance of endocrine tumours in multiple endocrine neoplasia type 1 (MEN1): a multicentre study of 258 gene carriers. Clinical Endocrinology 200767 613-622. (https://doi.org/10.1111/j.13652265.2007.02934.x)

24 Pieterman CRC, de Laat JM, Twisk JWR, van Leeuwaarde RS, de Herder WW, Dreijerink KMA, Hermus ARMM, Dekkers OM, van der Horst-Schrivers ANA, Drent ML, et al. Long-term natural course of small nonfunctional pancreatic neuroendocrine tumors in MEN1results from the Dutch MEN1 Study Group. Journal of Clinical Endocrinology and Metabolism 2017102 3795-3805. (https://doi. org/10.1210/jc.2017-00372)

25 Pieterman CRC, van Hulsteijn LT, den Heijer M, van der Luijt RB, Bonenkamp JJ, Hermus ARMM, Borel Rinkes IHM, Vriens MR, Valk GD, DutchMEN1 Study Group. Primary hyperparathyroidism in MEN1 patients: a cohort study with longterm follow-up on preferred surgical procedure and the relation with genotype. Annals of Surgery 2012255 1171-1178. (https://doi.org/10.1097/ SLA.0b013e31824c5145)

26 de Laat JM, Pieterman CR, van den Broek MF, Twisk JW, Hermus AR, Dekkers OM, de Herder WW, van der Horst-Schrivers AN, Drent ML, Bisschop PH, et al. Natural course and survival of neuroendocrine tumors of thymus and lung in MEN1 patients. Journal of Clinical Endocrinology and Metabolism 201499 3325-3333. (https://doi. org/10.1210/jc.2014-1560)

27 Pieterman CRC, Conemans EB, Dreijerink KMA, Laat JM De, Timmers HTM, Vriens MR \& Valk GD. Thoracic and duodenopancreatic neuroendocrine tumors in multiple endocrine neoplasia type 1: natural history and function of menin in tumorigenesis. Endocrine-Related Cancer 201421 R121-R142. (https:// doi.org/10.1530/ERC-13-0482)

28 Lodewijk L, Bongers PJ, Kist JW, Conemans EB, de Laat JM, Pieterman CRC, van der Horst-Schrivers ANA, Jorna C, Hermus AR, Dekkers OM, et al. Thyroid incidentalomas in patients with multiple endocrine neoplasia type 1. European Journal of Endocrinology, 
European Federation of Endocrine Societies 2015172 337-342. (https:// doi.org/10.1530/EJE-14-0897)

29 Nell S, van Leeuwaarde RS, Pieterman CRC, de Laat JM, Hermus AR, Dekkers OM, de Herder WW, van der Horst-Schrivers AN, Drent ML, Bisschop PH, et al. No association of blood type O With neuroendocrine tumors in multiple endocrine neoplasia Type 1. Journal of Clinical Endocrinology and Metabolism $20151003850-3855$. (https://doi.org/10.1210/jc.2015-2615)

30 de Laat JM, Dekkers OM, Pieterman CRC, Kluijfhout WP, Hermus AR, Pereira AM, van der Horst-Schrivers AN, Drent ML, Bisschop PH, Havekes B, et al. Long-term natural course of pituitary tumors in patients with MEN1: results from the DutchMEN1 Study Group (DMSG). Journal of Clinical Endocrinology and Metabolism $2015 \mathbf{1 0 0}$ 3288-3296. (https://doi.org/10.1210/JC.2015-2015)

31 van Leeuwaarde RS, van Nesselrooij BPM, Hermus AR, Dekkers OM, de Herder WW, van der Horst-Schrivers AN, Drent ML, Bisschop PH, Havekes B, Vriens MR, et al. Impact of delay in diagnosis in outcomes in MEN1: results from the Dutch MEN1 Study Group. Journal of Clinical Endocrinology and Metabolism 2016101 1159-1165. (https:// doi.org/10.1210/jc.2015-3766)

32 Nell S, Brunaud L, Ayav A, Bonsing BA, Groot Koerkamp B, Nieveen van Dijkum EJ, Kazemier G, de Kleine RHJ, Hagendoorn J, Molenaar IQ, et al. Robot-assisted spleen preserving pancreatic surgery in MEN1 patients. Journal of Surgical Oncology 2016114 456-461. (https://doi.org/10.1002/jso.24315)

33 Nell S, Borel Rinkes IHM, Verkooijen HM, Bonsing BA, van Eijck CH, van Goor H, de Kleine RHJ, Kazemier G, Nieveen van Dijkum EJ, Dejong CHC, et al. Early and late complications after surgery for MEN1-related nonfunctioning pancreatic neuroendocrine tumors. Annals of Surgery 2018267 352-356. (https://doi.org/10.1097/ SLA.0000000000002050)

34 Conemans EB, Nell S, Pieterman CRC, de Herder WW, Dekkers OM, Hermus AR, van der Horst-Schrivers AN, Bisschop PH, Havekes B, Drent ML, et al. Prognostic factors for survival of MEN1 patients with duodenopancreatic tumors metastatic to the liver: results form the DMSG Study Group. Endocrine Practice 201723 641-648. (https://doi. org/10.4158/EP161639.OR)

35 Nell S, Verkooijen HM, Pieterman CRC, De HWW, Hermus AR, Dekkers OM, Van Der Horst-Schrivers AN, Drent ML, Bisschop PH, Havekes B, et al. Management of MEN1 related nonfunctioning pancreatic NETs: a shifting paradigm: results from the DutchMEN1
Study Group. Annals of Surgery 2018267 1155-1160. (https://doi. org/10.1097/SLA.0000000000002183)

36 van Leeuwaarde RS, Dreijerink KM, Ausems MG, Beijers HJ, Dekkers OM, de Herder WW, van der Horst-Schrivers AN, Drent ML, Bisschop PH, Havekes B, et al. MEN1-dependent breast cancer: indication for early screening? Results from the Dutch MEN1 Study Group. Journal of Clinical Endocrinology and Metabolism 2017102 2083-2090. (https://doi.org/10.1210/jc.2016-3690)

37 van Leeuwaarde RS, de Laat JM, Pieterman CRC, Dreijerink KMA, Vriens M \& Valk GD. The future: advances in therapeutic approach and management strategies for MEN 1. Endocrine-Related Cancer 2017 24 T179-T193. (https://doi.org/10.1530/ERC-17-0225)

38 Conemans EB, Brosens LAA, Raicu-Ionita GM, Pieterman CRC, De Herder WW, Dekkers OM, Hermus AR, Van Der Horst-Schrivers AN, Bisschop PH, Havekes B, et al. Prognostic value of WHO grade in pancreatic neuro-endocrine tumors in Multiple Endocrine Neoplasia type 1: results from the DutchMEN1 study group. Pancreatology 2017 17 766-772. (https://doi.org/10.1016/j.pan.2017.07.196)

39 Conemans EB, Raicu-Ionita GM, Pieterman CRC, Dreijerink KMA, Dekkers OM, Hermus AR, de Herder WW, Drent ML, van der HorstSchrivers ANA, Havekes B, et al. Expression of p27Kip1 and p18Ink4c in human multiple endocrine neoplasia type 1-related pancreatic neuroendocrine tumors. Journal of Endocrinological Investigation 2018 41 655-661. (https://doi.org/10.1007/s40618-017-0783-y)

40 Manniën J, Ledderhof T, Verspaget HW, Snijder RR, Flikkenschild EF, Van Scherrenburg NPC, Stolk RP, Zielhuis GA \& The Parelsnoer Institute. A National Network of Standardized clinical biobanks in the Netherlands. Open Journal of Bioresources 201725 1-8.

41 van Leeuwaarde RS, Pieterman CRC, Bleiker EMA, Dekkers OM, van der Horst-Schrivers AN, Hermus AR, de Herder WW, Drent ML, Bisschop PH, Havekes B, et al. high fear of disease occurrence is associated with low quality of life in patients with multiple endocrine neoplasia type 1: results from the Dutch MEN1 Study Group. Journal of Clinical Endocrinology and Metabolism $2018 \mathbf{1 0 3}$ 2354-2361. (https://doi.org/10.1210/jc.2018-00259)

42 Conemans EB, Lodewijk L, Moelans CM, Offerhaus GJA, Pieterman CRC., Morsink FH, Dekkers OM, de Herder WW, Hermus AR, van der Horst-Schrivers ANA, et al. DNA methylation profiling in MEN1-related pancreatic neuroendocrine tumors reveals a potential epigenetic target for treatment. European Journal of Endocrinology 2018 179 153-160. (https://doi.org/10.1530/EJE-18-0195)

Received in final form 22 August 2018

Accepted 13 September 2018

Accepted Preprint published online 13 September 2018

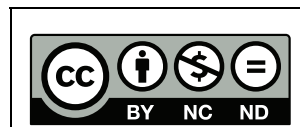

This work is licensed under a Creative Commons Attribution-NonCommercial-NoDerivatives 4.0 International License. 